\title{
A study of clinical manifestations and complications of dengue fever in medical college hospital
}

\author{
T Patil S. ${ }^{1}$, Virupaksha K.L. ${ }^{2 *}$, Kavyashree N. G. ${ }^{3}$ \\ DOI: https://doi.org/10.17511/ijmrr.2019.i03.13 \\ 1 Sanjay T Patil, Assistant professor, Department of Nephrology, Shri Dharmasthala Manjunatheshwara College of Medical Sciences \& \\ Hospital, Dharwad, Karnataka, India. \\ 2* Virupaksha K.L, Associate Professor, Department of General Medicine, Shridevi Institute of Medical Sciences \& Research Hospital, \\ Tumakuru, Karnataka, India. \\ 3 Kavyashree N. G, Assistant Professor, Department of Anaesthesiology, Shridevi Institute of Medical Sciences \& Research Hospital, \\ Tumakuru, Karnataka, India.
}

Background: Dengue, the most common arboviral disease worldwide is usually endemic but several epidemics have been recorded. Global incidence of dengue has grown dramatically in recent decades; about half of the world's population is now at risk. The situation in India is reflected by occurrence of major disease outbreaks from time to time over the last few decades. Objectives: The objective of the present study was to observe the various clinical manifestations and complications of dengue fever. Materials and Methods: Study included 100 patients admitted to medicine ward in medical college hospital for a period of 6 months with symptoms and signs suggestive of dengue fever and those positive for NS1Ag, IgM and IgG dengue antibodies using Rapid strip test. Results: Among 100 patients observed, majority cases were dengue fever (92\%) with no mortality, $5 \%$ were dengue hemorrhagic fever (DHF) with mortality $20 \%$ and $3 \%$ were dengue shock syndrome (DSS) with mortality 67\%. 71 were males and 29 were females with sex ratio 2.5:1. Maximum patients were in the age group of 18-30years. Most common clinical manifestations were fever (100\%), headache $(90 \%)$, abdominal pain $(72 \%)$, arthralgia (65\%), myalgia (64\%), hepatomegaly (52\%) and splenomegaly (41\%). Thrombocytopenia ( $84 \%)$ is the most common hematological abnormality observed. Conclusion: Dengue infection is common viral infection with varying clinical manifestations from region to region and epidemic to epidemic. Even though no specific treatment available for dengue fever but early diagnosis and timely intervention will prevent complications and mortality from dengue hemorrhagic fever and dengue shock syndrome

Keywords: Dengue fever, Fever, Bleeding manifestation, Thrombocytopenia, Hepatic dysfunction

Corresponding Author

Virupaksha K.L, Associate Professor, Department of General Medicine, Shridevi Institute of Medical Sciences \& Research Hospital, Tumakuru, Karnataka, India.

Email: viruk12008@gmail.com
How to Cite this Article

Patil ST, Virupaksha KL, Kavyashree NG. A study of clinical manifestations and complications of dengue fever in medical college hospital. Int J Med Res Rev. 2019;7(3):224-230.

Available From

https://ijmrr.medresearch.in/index.php/ijmrr/article/ view/1063
To Browse

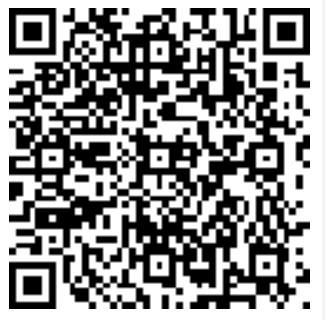

Manuscript Received 2019-05-14

Conflict of Interest No
Review Round 1 2019-05-24

Funding

$\mathrm{Nil}$

Review Round 2
2019-05-30
Ethical Approval
Yes

Review Round 3

Plagiarism X-checker $6 \%$
Accepted 2019-06-03

Note

(c) 2019 by Sanjay T Patil, Virupaksha K.L, Kavyashree N. G and Published by Siddharth Health Research and Social Welfare Society. This is an Open Access article licensed under a Creative Commons Attribution 4.0 International License https://creativecommons.org/licenses/by/4.0/ unported [CC BY 4.0]. 


\section{Introduction}

Dengue is common viral infection in developing country like India. The word "dengue" is derived from Swahili phraseka-dinga pepo means "cramp like seizure". First clinical case report was by Benjamin Rush in Philadelphia, who describes dengue as "Back bone fever" because of symptoms of myalgia and arthralgia [1].

Dengue is the most rapidly spreading mosquitoborne viral disease in the world. In the last 50 years, incidence has increased by 30 -fold with increasing geographic expansion to new countries and in the present decade, from urban to rural settings. An estimated 50 million dengue infections occur annually and approximately 2.5 billion people live in dengue endemic countries [2].

It is distributed worldwide throughout tropics and subtropics between $30 \circ \mathrm{N}$ and $40 \circ \mathrm{S}$ and endemic in South East Asia including India, Pakistan and Srilanka. Dengue is caused by four antigenically distinct viruses designated as dengue virus type 1-4 (DEN-1, DEN-2, DEN-3 and DEN-4) belonging to genus flavivirus of family flaviviridae. All the 4 serotypes of dengue viruses are primarily transmitted by aedes aegypti [3].

Symptomatic dengue virus infections can present with a wide range of clinical manifestations from mild febrile illness to life-threatening shock syndrome or organ dysfunction [4]. The patients with dengue fever typically present with the sudden onset of fever, frontal headache, retroorbital pain, and back pain along with severe myalgias-breakbone fever. Additional signs and symptoms include anorexia, nausea, vomiting, and cutaneous hypersensitivity. Epistaxis and scattered petechiae are often noted in uncomplicated dengue [5].

According to the WHO report, the mortality in untreated cases of dengue fever was reported to be as high as $20 \%$, while the hospitalized patients had a mortality rate of less than $1 \%$ [6]. So this study was undertaken to known the various clinical manifestations and complications of dengue fever.

\section{Materials and Methods}

Sources of data: Patients admitted to medicine wards in medical college hospital during the study period of 6 months with history of fever, other symptoms and signs suggestive of dengue fever.
Method of collection: Data was collected in a pretested proforma for hundred patients, who fulfilled WHO criteria for dengue fever, dengue hemorrhagic fever (DHF) and dengue shock syndrome (DSS). The clinical history, physical findings and laboratory investigations like Hemoglobin percentage $(\mathrm{Hb} \%)$, Total and differential WBC Count, Erythrocyte sediment rate (ESR), Hematocrit, Platelet count, Urine routine examination, Random blood glucose (RBS), Blood urea and serum creatinine, Serum electrolytes, Liver function test (LFT), Prothrombin time, Activated partial thromboplastin time (APTT), Chest X-ray, Ultrasonography (USG) abdomen, Electrocardiogram (ECG), Cerebrospinal fluid (CSF) analysis and Computed tomography (CT) Scan if required. NS1Ag (Non-structural protein), IgM and IgG dengue antibodies were estimated using Rapid strip test (J. Mitra \& co. Pvt. Ltd.) that helped in diagnosis of dengue fever.

\section{Inclusion Criteria}

01. Fever of acute onset, high degree, continuous, lasting for 2-7 days with associated symptoms specific to dengue fever such as headache, myalgia, retroorbital pain and arthralgia with positive for NS1Ag, IgM and IgG dengue antibodies using Rapid strip test (J. Mitra \& co. Pvt. Ltd.).

02. Fever with thrombocytopenia and hemorrhagic manifestations like petechiae, purpura, ecchymosis, epistaxis, gum bleeding, GI bleeding and sometimes intracerebral bleeding.

\section{Exclusion Criteria}

01. Thrombocytopenia due to other infectious diseases like malaria, leptospirosis, typhoid fever, rickettsia, chikungunya and HIV infection.

Statistical Methods: All the statistical calculation were performed using the software SPSS for windows (statistical presentation system software, SPSS Inc, 2010, New York) version 19.

\section{Results}

Table-1: Age and Sex distribution of cases $(\mathbf{N}=\mathbf{1 0 0})$

\begin{tabular}{|l|l|l|l|}
\hline \multirow{2}{*}{ Age (years) } & \multicolumn{2}{|c|}{ Sex } & \multirow{2}{*}{ Total (\%) } \\
\cline { 2 - 3 } & Males (\%) & Females (\%) & \\
\hline $18-30$ & $29(40.8)$ & $9(31.0)$ & $38(38)$ \\
\hline $31-40$ & $19(26.8)$ & $12(41.4)$ & $31(31)$ \\
\hline $41-50$ & $14(19.7)$ & $5(17.2)$ & $19(19)$ \\
\hline $51-60$ & $6(8.5)$ & $2(6.9)$ & $8(8)$ \\
\hline
\end{tabular}


Patil ST. et al: A study of clinical manifestations and complications

\begin{tabular}{|l|l|l|l|}
\hline$>60$ & $3(4.2)$ & $1(3.5)$ & $4(4)$ \\
\hline Total & $71(100)$ & $29(100)$ & $100(100)$ \\
\hline
\end{tabular}

In the present study, there were 71 males and 29 females with sex ratio of $2.5: 1$. It was observed that among males maximum (40.8\%) were in the age group of $18-30$ years followed by $26.8 \%$ in the group of $31-40$ years, $19.7 \%$ in the age group of 41-50 years and minimum were in the age group of $>60$ years $(4.2 \%)$.

Among females, the maximum $(41.4 \%)$ were in the age group of $31-40$ years followed by $18-30$ years $(31.0 \%), 41-50$ years $(17.2 \%)$ and minimum was in the age group of $>60$ years $(3.5 \%)$.

Table-2: Clinical symptoms of study population

\begin{tabular}{|l|l|l|l|}
\hline \multirow{2}{*}{ Symptoms } & \multicolumn{2}{|c|}{ Sex } & \multirow{2}{*}{ Total (\%) } \\
\cline { 2 - 3 } & Males (\%) & Females (\%) & \\
\hline Fever & $71(100)$ & $29(100)$ & $100(100)$ \\
\hline Headache & $64(90)$ & $26(90)$ & $90(90)$ \\
\hline Myalgia & $44(62)$ & $20(70)$ & $64(64)$ \\
\hline Arthralgia & $49(69)$ & $16(55)$ & $65(65)$ \\
\hline Abdominal pain & $49(60)$ & $22(76)$ & $71(71)$ \\
\hline Nausea and vomiting & $43(61)$ & $16(55)$ & $59(59)$ \\
\hline Retro-orbital pain & $36(51)$ & $10(35)$ & $46(46)$ \\
\hline Skin rashes & $29(41)$ & $6(20)$ & $35(35)$ \\
\hline Jaundice & $21(30)$ & $2(7)$ & $23(23)$ \\
\hline Bleeding manifestations & $20(28)$ & $3(10)$ & $23(23)$ \\
\hline Dyspnoea & $5(7)$ & $0(0)$ & $5(5)$ \\
\hline
\end{tabular}

In the present study the most common presenting symptoms were fever $(100 \%)$ followed by headache $(90 \%)$, abdominal pain $(71 \%)$, myalgia (64\%), arthralgia (65\%), nausea and vomiting (59\%), retroorbital pain $(46 \%)$, skin rashes $(35 \%)$, bleeding manifestations (23\%-like epistaxis, gum bleeding, haematuria, malena and haematemesis) and jaundice (23\%).

The least common symptom observed was dyspnoea (5\%). 5 patients had developed dyspnoea, among them 3 showed features of acute respiratory distress syndrome (ARDS) and were on ventilators and died despite of optimum therapy.

Table-3: Clinical signs of study population

\begin{tabular}{|l|l|l|l|}
\hline \multirow{2}{*}{ Signs } & \multicolumn{2}{|c|}{ Sex } & \multirow{2}{*}{ Total (\%) } \\
\cline { 2 - 3 } & Male (\%) & Female (\%) & \\
\hline Bradycardia & $4(6)$ & $2(7)$ & $6(6)$ \\
\hline Hypotension & $5(7)$ & $0(0)$ & $5(5)$ \\
\hline Pallor & $8(11)$ & $2(7)$ & $10(10)$ \\
\hline Icterus & $14(20)$ & $3(11)$ & $17(17)$ \\
\hline Cyanosis & $1(2)$ & $0(0)$ & $1(1)$ \\
\hline Lymphadenopathy & $32(45)$ & $7(24)$ & $39(39)$ \\
\hline
\end{tabular}

\begin{tabular}{|l|l|l|l|}
\hline Rashes & $10(14)$ & $2(7)$ & $12(12)$ \\
\hline Bleeding signs & $20(28)$ & $3(10)$ & $23(23)$ \\
\hline Free fluid (ascites) & $10(14)$ & $2(7)$ & $12(12)$ \\
\hline Hepatomegaly & $45(63)$ & $7(24)$ & $52(52)$ \\
\hline Splenomegaly & $33(47)$ & $8(28)$ & $41(41)$ \\
\hline Hepatosplenomegaly & $19(27)$ & $6(21)$ & $25(25)$ \\
\hline
\end{tabular}

In the present study most of the patients presented with lymphadenopathy (39\%), followed by bleeding signs (23\% - purpura, petechie and ecchymosis), icterus $(17 \%)$, skin rashes such as maculopapular rashes $(12 \%)$, pallor $(10 \%)$, bradycardia $(6 \%)$, hypotension ( $5 \%-\mathrm{SBP}<90 \mathrm{~mm}$ of $\mathrm{Hg}$ ) and cyanosis (1\%). Among 100 cases, $52 \%$ patients had only hepatomegaly, $41 \%$ patients had only splenomegaly and $25 \%$ patients had both hepatosplenomegaly. $12 \%$ patients had free fluid (ascites).

\section{Table-4: Hematological observations}

\begin{tabular}{|l|l|l|l|}
\hline \multirow{2}{*}{ Investigations } & \multicolumn{2}{|c|}{ Sex } & \multirow{2}{*}{ Total } \\
\cline { 2 - 4 } & Male (\%) & Female (\%) & \\
\hline Hemoglobin [Hb \%] $(<10 \mathrm{~g} \%)$ & $9(13)$ & $3(10)$ & $12(12)$ \\
\hline Haematocrit [Hct] $(>45 \%)$ & $25(35)$ & $5(18)$ & $30(30)$ \\
\hline Total count [TC] (<4000 cells/cu.mm) & $47(67)$ & $8(28)$ & $55(55)$ \\
\hline Platelet count (<1.5 lakhs/cu.mm) & $67(94)$ & $17(59)$ & $84(84)$ \\
\hline Liver function test [LFT] (deranged) & $26(37)$ & $7(24)$ & $33(33)$ \\
\hline
\end{tabular}

In the present study, out of 100 patients $84 \%$ patients had thrombocytopenia (platelet count $<1.5$ lakhs/cu.mm), 55\% patients had leucopenia (TC < 4000 cells/cu.mm), 30\% patients had increased haematocrit $(>45 \%), 33 \%$ patients had deranged LFT and $12 \%$ patients were anemic ( $\mathrm{Hb} \%<10 \mathrm{~g} \%)$.

Table-5: Cases depending upon platelet count

\begin{tabular}{|l|l|l|}
\hline Platelet Count (cells/cu.mm) & Number of patients & Percentage \\
\hline Below 20,000 & 9 & 9 \\
\hline $20,000-50,000$ & 13 & 13 \\
\hline $50,000-1,00,000$ & 53 & 53 \\
\hline 1.0 lakh-1.5 lakhs & 9 & 9 \\
\hline$>1.5$ lakhs & 16 & 16 \\
\hline Total & 100 & 100 \\
\hline
\end{tabular}

Among 100 patients $53 \%$ patients had platelet count between 50,000-1.0 lakh, 16\% patients had $>1.5$ lakhs, $13 \%$ patients had between 20,00050,000 and only $9 \%$ patients had platelet count below 20,000.

\section{Table-6: Serology findings}

\begin{tabular}{|l|l|l|}
\hline \multicolumn{1}{|c|}{ Serology } & Number of patients & Percentage \\
\hline NS1 & 81 & 81 \\
\hline IgM & 7 & 7 \\
\hline Mixed (NS1\& IgM \pm IgG) & 12 & 12 \\
\hline Total & 100 & 100 \\
\hline
\end{tabular}


Out of 100 patient's dengue serology positive cases, $81 \%$ patients were positive for NS1 antigen, 7\% patients were positive for IgM antibodies and rest $12 \%$ patients were with mixed positivity.

\section{Table-7: Complications of dengue}

\begin{tabular}{|l|l|}
\hline \multicolumn{1}{|c|}{ Complications } & Number of patients \\
\hline Acute respiratory distress syndrome (ARDS) & 3 \\
\hline Pleural effusion & 27 \\
\hline Hepatic dysfunction & 33 \\
\hline Abnormal coagulation profile & 7 \\
\hline Acute renal failure (ARF) & 2 \\
\hline Encephalopathy & 3 \\
\hline
\end{tabular}

In the present study $33 \%$ patients showed hepatic dysfunction, $27 \%$ patients showed pleural effusion. Abnormal coagulation profile was noted in $7 \%$ of patients, $2 \%$ patients were in acute renal failure and $3 \%$ of patients developed acute respiratory distress syndrome (ARDS) and $3 \%$ had neurological manifestation like encephalopathy.

Table-8: Dengue manifestations

\begin{tabular}{|l|l|l|}
\hline \multicolumn{1}{|c|}{ Dengue manifestations } & Number of patients & Mortality \\
\hline Dengue fever & 92 & 0 \\
\hline Dengue hemorrhagic fever (DHF) & 5 & 1 \\
\hline Dengue shock syndrome (DSS) & 3 & 2 \\
\hline
\end{tabular}

In the present study among 100 cases, 92\% patients had dengue fever with no mortality, $5 \%$ patients had dengue hemorrhagic fever (DHF) with $20 \%$ mortality and 3\% patients had dengue shock syndrome (DSS) with $67 \%$ mortality.

\section{Discussion}

Dengue infection is now escalating problem and is emerging or reemerging as a major health problem in most parts of South East Asia including India.

Age: The maximum prevalence was noticed in the age group of $18-30$ years (38\%). This indicates that the disease affects younger and productive age group. The incidence of age group is similar to studies conducted by Gupta E et al [7] (21 to 30 years) and Doke P \& Pawar S [8] (15-40 years).

Sex: Males outnumbered females, this is partly because in India they are less covered by clothes than females and also they move out of their place more commonly than females thus exposing themselves to mosquitoes bites. In the present study male to female ratio is 2.5:1 which is similar to the study conducted by Deshwal $\mathrm{R}$ et al [9], which observed male to female ratio of $2.67: 1$.
Clinical Manifestations: In the present study the most common presenting symptoms were fever $(100 \%)$ followed by headache $(90 \%)$, myalgia $(64 \%)$, arthalgia (65\%), nausea and vomiting $(59 \%)$, retroorbital pain $(46 \%)$, jaundice $(23 \%)$, bleeding manifestations (23\%- epistaxis, gum bleeding, haematuria, malena and haematemesis) and dysponea (5\%).

Laul A et al [10] study observed fever (100\%), headache $(87 \%)$, bodyache $(86 \%)$, backache $(58 \%)$, retro-orbital pain $(41 \%)$, vomiting $(68 \%)$, abdominal pain $(57 \%)$, rash $(21 \%)$, bleeding manifestations (21\%) and dysponea (19\%). Kumar A et al [11] study observed fever (99.1\%) as most common symptom followed by myalgia (64.6\%), vomiting $(47.6 \%)$ and bleeding manifestation (26.6\%). Itoda I et al [12] study headache was observed in $90 \%$ patients. In the present study abdominal pain was observed in $71 \%$, Daniel $\mathrm{R}$ et al [13] observed abdominal pain in $62.4 \%$. In the present study $35 \%$ patients had skin rashes which are all most similar observation with Mandal S K et al [14] study who observed skin rashes in $37.84 \%$. In the present study $25 \%$ had hepatosplenomegaly, similar to study by Laul A et al [10].

Hematological observations: In the present study most common hematological observation was thrombocytopenia (platelet count < 1.5 lakhs/cumm) in $84 \%$. Study by Seema $A$ et al [15] showed thrombocytopenia in $84 \%$. In the present study $55 \%$ patients showed leucopenia, 30\% increased haematocrit, 33\% deranged LFT and $12 \%$ were anemic. Study by Daniel R et al [13] observed anemia in $6 \%$, leucopenia in $40 \%$, increased haematocrit in $27.9 \%$ and deranged LFT in $84 \%$.

Dengue manifestations: Present study showed dengue fever in $92 \%$, DHF in 5\% and DSS in 3\%. In a study by Sharma S and Sharma SK [16] DHF was in $10.5 \%$ and DSS was in $3.2 \%$. DF observed in $73 \%$ cases, DHF in $16.5 \%$ and DSS in $1.7 \%$ in a study by Laul $A$ et al [10]. In the present study showed dengue fever as most common manifestation.

Serology: Present study showed NS1 antigen positive in $81 \%$, IgM antibody positive in $7 \%$ and mixed serology in $12 \%$. Khan $\mathrm{S} A$ et al [17] study showed NS1 $91.5 \%$, IgM $4.6 \%$, both NS1 and IgM positive in $3.7 \%$.

Complications: In the present study majority patients showed hepatic dysfunction (33\%), who improved after fluid resuscitation. 
Wiwanitki $V$ [18] study observed overall rate of liver dysfunction in $34.6 \%$. In the present study $27 \%$ had pleural effusion, abnormal coagulation profile was noted in $7 \%$ of patients, $2 \%$ patients were in acute renal failure who improved after resuscitation without dialysis. $3 \%$ of patients developed ARDS, but none of them survived inspite of possible treatment. Vasireddy $S$ et al [19] study showed pleural effusion (30\%), hypotension (14\%), pneumonia $(10 \%)$, renal failure $(3 \%)$, ARDS $(3 \%)$. In the present study $3 \%$ had neurological manifestation like encephalopathy. Verma $\mathrm{R}$ et al [20] study observed that $15.3 \%$ patients had encephalopathy.

Mortality: In present study mortality rate was $3 \%$. Similar mortality rate of $3.2 \%$ and $4.14 \%$ were found in other Indian studies [7, 13].

\section{Conclusion}

Dengue infection is still a major public health problem in tropical and subtropical countries. There is increase in incidence day by day, becoming endemic in developing countries like India because of poor sanitation, rapid urbanization, insecticide resistance and lack of health education. In the present study showed dengue infection commonly affects young and male population. Majority cases are simple dengue fever which requires symptomatic treatment and others severe form like dengue hemorrhagic fever and dengue shock syndrome requires timely intervention.

Nowadays clinical manifestations and complications varies from region to region, from epidemic to epidemic. Some of known clinical features are still manifesting, few uncommon features are noted from several parts of world. So a continuous seroepidemiological surveillance, early identification and proper confirmation of diagnosis of dengue infection will prevent complications and mortality.

\section{What this study adds to existing knowledge?}

The inference from the above study is majority cases were simple dengue fever with common clinical manifestation like fever, headache, arthralgia, myalgia and abdominal pain with no mortality, where as few cases were dengue hemorrhagic fever and dengue shock syndrome with mortality and common complication noted was hepatic dysfunction.
So it requires continuous sero-epidemiological surveillance for early identification and proper diagnosis of dengue infection to prevent complications and mortality.

\section{Contribution by authors}

Dr Sanjay T Patil- Study concepts and design. Guiding the study procedure

Dr Virupaksha K L- Conducting study and writing manuscript

Dr Kavyashree N G- Manuscript editing and review that suitable for publication. statistical analysis.

\section{Reference}

01. Guzman MG, Kouri G. Dengue- an update. Lancet Infect Dis. 2002 Jan;2(1)33-42.

[Crossref]

02. Nathan M B, Drager R D, Guzman M G. DengueGuidelines for diagnosis, treatment, prevention and control. Geneva- World Health Organization. 2009;1;03-11.

[Crossref]

03. P K Dash, M M Parida, P Saxena, A Abhyankar, C P Singh, K N Tewari, A M Jana, K Sekhar, P V Lakshmana Rao. Reemergence of dengue virus type-3 (subtype III) in India; Implications for increased incidence of DHF and DSS. Virology Journal. 2006 Feb;3;55.

doi: 10.1186/1743-422X-3-55 [Crossref]

04. WHO Regional Office for Southeast Asia. Comprehensive Guidelines for Prevention and Control of Dengue and Dengue Haemorrhagic Fever, Revised and expanded version. New Delhi, India- SEARO Technical Publication Series. 2011.

[Crossref]

05. Kuhn JH, Peters CJ. Arthropod-borne and rodent-borne virus infections, In- Kasper DL, Fauci AS, Hauser SL, Longo DL, Jameson JL, Loscalzo J, Editors, Harrison's Principles of Internal Medicine. McGraw-Hill Education; Columbus, OH, USA. 19th ed, 2;2015.

Ch 233;1304-23 [Crossref]

06. World Health Organization. Report on global surveillance of epidemic-prone infectious diseases. WHO. 2001.

Available at: [Article] [Crossref] 
07. Gupta E, Dar L, Kapoor G, Broor S. "The changing epidemiology of dengue in Delhi, India. " virology Journal. 2006 Nov;3;92.

[Article] [Crossref]

08. Doke P, Pawar S. Profile of Dengue fever outbreaks in Maharashtra. Indian J Community Med. 2000 Oct-Dec;25(4)170-76.

[Crossref]

09. Deshwal R, Qureshi MI, Singh R. Clinical and Laboratory Profile of Dengue Fever. J Assoc Physicians India. 2015 Dec;63(12)30-32. [Crossref]

10. Laul A, Laul P, Merugumala V, et al. Clinical Profiles of Dengue Infection during an Outbreak in Northern India. J Trop Med. 2016;5917934. doi: 10.1155/2016/5917934 [Crossref]

11. Kumar A, Rao C R, Pandit V, Shetty S, Bammigatti $C$, Samarasinghe C M. Clinical manifestations and trend of dengue cases admitted in a tertiary care hospital, udupi district, Karnataka. Indian Journal of Community Medicine. 2010 Jul-Sep;35(3)386-90.

DOI: $10.4103 / 0970-0218.69253$ [Crossref]

12. Itoda I, Masuda G, Suganuma A, Imamura $A$, Ajisawa A, Yamada K. Clinical features of 62 imported cases of dengue fever in Japan. Am J Trop Med Hyg. 2006;75(3)470-4.

doi: 10.4269/ajtmh.2006.75.470 [Crossref]

13. Daniel R, Rajmohanan, and Philip A Z. A study of clinical profile of dengue fever in Kollam, Kerala, India. Dengue Bulletin. 2005;29;195-02. [Crossref]

14. Mandal S K, Ganguly J, Koelina Sil, Sumanta C, Kaushik C, Pankaj S, Shatanik H, Debasis S. Clinical profiles of dengue fever in a teaching hospital of eastern india. Natl J Med Res. 2013;3(2)173-76.

[Crossref]
15. Seema A, Singh V K, Kumar S, Kumar A, Dutta S. The Changing Clinical Spectrum of Dengue Fever in the 2009 Epidemic in North India- A Tertiary Teaching Hospital Based Study. Journal of Clinical and Diagnostic Research. 2012 Aug;6(6)999-1002.

[Crossref]

16. Sharma S, Sharma SK. Clinical profile of DHF in adults during 1996 outbreak in Delhi, India. Dengue Bulletin. 1998;22;20-27.

[Crossref]

17. Khan S A, Dutta P, Topno R, Soni M, Mahanta J. Dengue Outbreak in a Hilly State of Arunachal Pradesh in Northeast India. The Scientific World J. 2014.

Doi: $10.1155 / 2014 / 584093$ [Crossref]

18. Wiwanitki V. liver dysfunction in dengue infection, an analysis of the previously published thai cases. J Ayub Med Coll Abbottabad. 2007 Jan- Mar;19(1)10-12.

[Crossref]

19. Vasireddy S, Kodali A, Kiran Reddy B M, Eswar G. Clinical Profile of Dengue Infection at a Teaching Hospital in South India. IOSR Jour of Den and Med Scie. 2017 Mar;16(3)52-56.

DOI: $10.9790 / 0853-1603025256 \quad$ [Crossref]

20. Verma R, Sharma P, Garg R K, Atam V, Singh M $\mathrm{K}$, Mehrotra H S. Neurological complications of dengue fever- Experience from a tertiary center of north india. Ann Indian Acad Neurol. 2011 Oct-Dec; $14(4) 272-78$.

DOI: $10.4103 / 0972-2327.91946$ [Crossref] 